Revista Brasileira de Farmacognosia Brazilian Journal of Pharmacognosy 21(5): 874-883, Sep./Oct. 2011

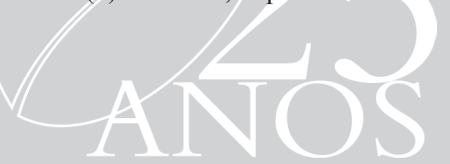

Article

Received 8 Mar 2011

Accepted 17 Jul 2011

Available online 2 Sep 2011

Keywords:

Vitex cymosa

Verbenaceae sensu lato

Lamiaceae sensu lato

antinociceptive activity

medicinal plants

flavonoids

triterpene acids

iridoids

ISSN 0102-695X

http://dx.doi.org/10.1590/S0102-

695X2011005000160

\section{Phytochemical profile and analgesic evaluation of Vitex cymosa leaf extracts}

\author{
Suzana Guimarães Leitão, ${ }^{*, 1}$ Tereza Cristina dos Santos, ${ }^{\#, 2}$ \\ Franco Delle Monache, ${ }^{4}$ Maria Eline Matheus, ${ }^{3}$ Patrícia Dias \\ Fernandes, ${ }^{3}$ Bruno Guimarães Marinho ${ }^{3}$
}

\author{
${ }^{I}$ Faculdade de Farmácia, Departamento de Produtos Naturais e Alimentos, \\ Universidade Federal do Rio de Janeiro, Brazil, \\ ${ }^{2}$ Núcleo de Pesquisas de Produtos Naturais, Universidade Federal do Rio de \\ Janeiro, Rio de Janeiro, Brazil, \\ ${ }^{3}$ Departamento de Farmacologia, ICB, Universidade Federal do Rio de Janeiro, \\ Brazil, \\ ${ }^{4}$ Dipartimento di Studi di Chimica e Tecnologia delle Sostanze Biologicamente \\ Attive, Università La Sapienza. Italy.
}

\begin{abstract}
Vitex cymosa Bertero ex Spreng., Lamiaceae, is found in Central and Amazon regions of Brazil, where it is popularly used as antirheumatic. Extracts from the leaves of $V$. cymosa were tested in analgesia models such as abdominal contortions induced by acetic acid and formalin to test peripheral analgesia; as well as the tail flick and hot plate models, to test spinal and supraspinal analgesia. A significant reduction was observed in the number of contortions with all extracts and in all doses. In the formalin model, a reduction in the second phase (inflammatory) was observed with all extracts, whereas only the $n$-butanol extract was able to act in the first, neurogenic, phase. In the tail flick model, all extracts increased latency time. Naloxone treatment reverted analgesic effect of all extracts with the exception of the dichloromethane one. All extracts developed peripheral and central analgesic activity. In the hot plate model no antinociceptive effect was observed for all tested extracts. All these results taken together suggest that $V$. cymosa leaf extracts were able to promote peripheral and central antinociceptive activity mediated by the opioid system. Twenty three substances were isolated and identified in the extracts and include flavonoids ( $C$-glucosyl flavones, flavones and flavonols), triterpene acids from ursane and oleanane types, iridoids (free and glucosides), as well as simple phenols.
\end{abstract}

\section{Introduction}

Vitex genus, Lamiaceae, (the genus has been formerly included in the Verbenaceae s.l. and recently transferred to the Lamiaceae s.l.) is constituted by small trees or shrubs occurring in tropical and subtropical regions. Many species have been studied in relation their chemistry, which is characterized by the presence of $C$-glucosyl flavones, ecdysteroids, diterpenes and iridoids (Brito, 1992), as well as in relation to their biological activities. Antiinflammatory (Sidhartha et al., 1990; Chawla, et al., 1991), wound healing (Sidhartha et al., 1990) and antiandrogenic (Bhargava, 1989) activities, as well as inhibition of lymphocyte proliferation (You et al., 1998) and smooth muscle relaxant effect (Dayrit et al., 1987; Dayrit \& Lagurin, 1994) are among those described in literature. V. agnus-castus is actually used in the treatment of pre-menstrual syndrome and menopausal complaints (Mills \& Bone, 2000). Despite the fact that the genus is well represented in Brazil with c.a. 35 species (Leitão et al., 2008), as far as we know, only three species have been chemically or pharmacologically investigated so far (Leitão et al., 2008, Gallo et al., 2008; 2006, Sá Barreto et al., 2005, Gonçalves et al., 2001). Vitex cymosa Bertero is a small tree widely distributed in the Central and Amazon regions of Brazil, where it is popularly known as "tarumã-do-igapó" and "tarumã-do-alagado" (Correa, 1926). The species are used by the native populations of the State of Maranhão to treat rheumatic pains. In a previous work done by our group (Miranda et al., 2010) extracts from this plant's barks, collected at Maranhão State, Brazil, were tested in antinociceptive models, such as the tail flick test, to evaluate the central analgesic effect. In this work a significant antinociceptive activity for the dichloromethane extract was observed. The (+)-trans-4-hydroxy-6-propyl-1-oxocyclohexan-2-one 
was isolated and determined to be the active principle. In this work we investigated the analgesic properties of the dichloromethane leaf extracts of this plant.

\section{Materials and Methods}

\section{Plant material}

Leaves of Vitex cymosa Bertero ex Spreng., Lamiaceae, were collected in Corumbá, Mato Grosso do Sul State, Brazil in December (in fruit). The plant was identified by Dr. Vali Pott, from Embrapa, Corumbá. A voucher specimen was deposited at Universidade Federal de Juiz de Fora herbarium under number CESJ 11,711.

\section{Plant extracts}

Dried and pulverized leaves $(2.2 \mathrm{~kg})$ were exhaustively extracted with ethanol. After filtration and concentration under reduced pressure the aqueous residue was sequentially extracted with organic solvents of increasing polarities, to afford the new extracts: dichloromethane (VD), ethyl acetate (VA) and $n$-butanol (VB) extracts, in this order, as well as (LW), which is the water-soluble remaining extract.

\section{Isolation and identification of substances from the extracts}

\section{Dichloromethane extract (VD)}

Part of VD was first chromatographed on silica gel eluted with $\mathrm{CH}_{2} \mathrm{Cl}_{2}$ with increasing amounts of EtOAc. Fractions eluted with $\mathrm{CH}_{2} \mathrm{Cl}_{2}$-EtOAc (9:1) were re-chromatographed on Sephadex LH-20 (MeOH) yielding 21. Fractions eluted with $\mathrm{CH}_{2} \mathrm{Cl}_{2}$-EtOAc $(8: 2)$ were purified by prep. TLC $\left(\mathrm{CH}_{2} \mathrm{Cl}_{2}\right.$-EtOAc, 3:1) to afford 1, and 2. Fractions eluted with $\mathrm{CH}_{2} \mathrm{Cl}_{2}$-EtOAc (7:3) were re-chromatographed on Sephadex LH-20 (MeOH), yielding 3. A second fractionation of VD was performed by $\mathrm{CC}$ on silica gel eluted with $\mathrm{CHCl}_{3}$ with increasing amounts of EtOAc, and with EtOAc with increasing amounts of $\mathrm{MeOH}$. Fractions eluted with $\mathrm{CHCl}_{3}$ were re-chromatographed on silica gel to afford 4, 13, and a mixture of $\mathbf{1 5}$ and $\mathbf{1 7}(\mathrm{CHCl} 3-\mathrm{EtOAc}$ 1:1). Fractions eluted with $\mathrm{CHCl}_{3}$-EtOAc 9:1 were re-chromatographed on Sephadex LH-20 (MeOH) affording a mixture of $\mathbf{1 6}$ and 18, as well as 5. Fractions eluted with EtOAc$\mathrm{MeOH}$ 8:2 were re-chromatographed in silica gel with the organic phase of a mixture of EtOAc-acetone $-\mathrm{H}_{2} \mathrm{O}$ (25:8:2), further purified on Sephadex LH-20 and, finally, by prep. TLC to afford $\mathbf{2 3}$ and $\mathbf{2 0}$. A third fractionation of VD was directly subjected to Sephadex LH-20 (MeOH) and led to the isolation of $\mathbf{1 9 .}$

\section{Ethyl acetate extract (VA)}

VA was chromatographed on silica gel eluted with the organic phase of a mixture of EtOAc-acetone$\mathrm{H}_{2} \mathrm{O}(25: 8: 2$ to $25: 10: 5)$ affording sisteen fractions. From the first two fractions, 12 and 14, were obtained by crystallization, respectively. From fraction $\mathbf{6 , 1 0}$ and 11 were obtained by prep. HPLC (see conditions below). From fractions 12-13, a mixture of the flavonoids 6, and 7, was obtained by crystallization and, from fraction $\mathbf{1 5}$, the flavonoids $\mathbf{8}$, and $\mathbf{9}$, were further purified by prep. TLC.

\section{Butanol extract (VB)}

VB was fractionated by silica gel CC eluted with $\mathrm{CHCl}_{3}$ with increasing amounts of $\mathrm{MeOH}$ affording 21, 22 and 23, as described previously (Santos et al., 2001). From fractions 10-16 $\left(\mathrm{CHCl}_{3}-\mathrm{MeOH} 9: 1\right) \mathbf{6}$, was obtained, and fractions 17-18 afforded 7.

Animals

All experiments were performed with male Swiss mice (20-25 g) obtained from our own animal facility. Animals were maintained in a room with controlled temperature $22 \pm 2{ }^{\circ} \mathrm{C}$ for $12 \mathrm{~h}$ light/dark cycle with free access to food and water. Twelve hours before each experiment animals received only water, in order to avoid food interference with substances absorption. Animal care and research protocols were in accordance with the principles and guidelines adopted by the Brazilian College of Animal Experimentation (COBEA) and approved by the Biomedical Science Institute/UFRJ - Ethical Committee for Animal Research.

\section{Drugs and extracts administration}

All extracts used were administered by oral gavage at concentrations of 10,30 and $100 \mathrm{mg} / \mathrm{kg}$ in a final volume of $0.1 \mathrm{~mL}$. Morphine and dipyrone were used as reference drugs and were administered by oral gavage. The control group was composed by PBS with the same amount of DMSO used in the dose of $100 \mathrm{mg} / \mathrm{kg}$ of extracts $(0.005 \%)$ and had no effect per se. Naloxone was administered i.p. $15 \mathrm{~min}$ before oral administration of morphine or extracts.

\section{Acute toxicity}

Acute toxicity was determined following the experimental model described by Lorke (1983). A single oral dose of extracts $(500 \mathrm{mg} / \mathrm{kg})$ was administered to a group of ten mice (five males and five females). Behavior parameters including convulsion, hyperactivity, sedation, 
grooming, loss of righting reflex, increased or decreased respiration, and food and water intake were observed over a period of five days. After this period animals were killed by cervical dislocation, stomachs were removed, an incision along the greater curvature was made, and the number of ulcers (single or multiple erosion, ulcer or perforation) and hyperemia was counted.

\section{Acetic acid-induced abdominal writhing}

Mice were used according to Matheus et al. (2006). Briefly, the total number of writhings following intraperitoneal (i.p.) administration of $2 \%(\mathrm{v} / \mathrm{v})$ acetic acid (AA) was recorded over a period of $20 \mathrm{~min}$, starting 5 min after AA injection. The animals were pretreated orally with extracts or vehicle, $60 \mathrm{~min}$ before administration of AA.

\section{Formalin test}

The procedure was similar to the method described by Gomes et al. (2007). Animals received the injection of $20 \mu \mathrm{L}$ of formalin $(2.5 \% \mathrm{v} / \mathrm{v})$ into dorsal surface of the left hind paw. Immediately, the time that the animal spent licking the injected paw was recorded. The nociceptive response develops two phases: 0 to 5 min after formalin injection (first phase, response to neurogenic pain), and 15 to $30 \mathrm{~min}$ after formalin injection (second phase, response to inflammatory pain). For comparison purposes, the IC50 of morphine was calculated as 1.7 $\mathrm{mg} / \mathrm{kg}$. The animals were pre-treated with oral dose of extracts (10 to $100 \mathrm{mg} / \mathrm{kg}$ ), vehicle or morphine $(1.7 \mathrm{mg}$ / $\mathrm{kg}), 60 \mathrm{~min}$ before administration of formalin.

\section{Tail-flick test}

The procedure used was similar to Matheus et al. (2006). Briefly, mice tails were immersed on a water bath set at temperature of $50 \pm 1{ }^{\circ} \mathrm{C}$. The time necessary for the mice to withdrawal the tail, in seconds (named reaction time) was registered at 20, 40, 60, 80, 100 and $120 \mathrm{~min}$ after administration of $V$. cymosa extracts (10, 30 and $100 \mathrm{mg} / \mathrm{kg}$ ) or morphine $(2.3 \mathrm{mg} / \mathrm{kg})$. For comparison purposes, the IC50 of morphine was calculated as 2.3 $\mathrm{mg} / \mathrm{kg}$. Baseline was considered as the mean of reaction time obtained at 40 and $20 \mathrm{~min}$ before administration of $V$. cymosa extracts or morphine, and was defined as normal reaction of animal to the temperature. Increase in baseline (in \%) was calculated by the formula: (reaction time x 100)/baseline) - 100 .

\section{Hot plate test}

Mice were tested according to the method described by Matheus et al. (2006). The animals were placed on a hot plate set at $55 \pm 1{ }^{\circ} \mathrm{C}$. Reaction time was recorded when the animals licked their fore- and hindpaws and jumped, at 30, 60, 90, 120, 150 and $180 \mathrm{~min}$ after oral administration of $V$. cymosa extracts $(100 \mathrm{mg}$ / $\mathrm{kg}$ ) or morphine $(1 \mathrm{mg} / \mathrm{kg})$. Baseline was considered as the mean of reaction time obtained at 60 and $30 \mathrm{~min}$ before administration of extracts or morphine and was defined as normal reaction of animal to the temperature. Increase in baseline (in \%) was calculated by the formula: (reaction time x 100)/baseline) - 100 .

Evaluation of the mechanism of action of Vitex cymosa extracts

To evaluate the mechanism of action of $V$. cymosa extracts, animals were pre-treated with naloxone, a non-selective opioid antagonist. Naloxone $(5 \mathrm{mg} / \mathrm{kg})$ was administered i.p. 15 min before oral administration of extracts $(30 \mathrm{mg} / \mathrm{kg})$ or morphine $(2.3 \mathrm{mg} / \mathrm{kg})$.

\section{Statistical analysis}

All experimental groups were composed by ten animals. The results are presented either as the mean $\pm \mathrm{SD}$ in acetic acid-induced writhing and formalin or as the increase in baseline (\%) in tail flick test. Statistical significance between groups was performed by the application of analysis of variance ANOVA followed by Bonferroni's test. $p$ values less than $0.05(p<0.05)$ were used as the significant level.

\section{Results}

\section{Phytochemical identification of known compounds}

Phytochemical investigation of Vitex cymosa leaf extracts led to the isolation and identification of a number of known iridoids, triterpenes and flavonoids, which are secondary metabolites commonly found in the genus. Their chemical structures were identified by means of one and two dimensional ${ }^{1} \mathrm{H}$ and ${ }^{13} \mathrm{C}$ NMR techniques, as well as by mass spectral data, which were in accordance with previously reported data. From the dichloromethane extract, VD, the iridoids tarumal, 21 (Santos et al., 2001) and agnuside, 23 (Boros \& Stermitz, 1990); the flavonoids kampferol, 1, 3'-O-methyl-luteolin, 2, luteolin, 3, pachypodol, 4, and apigenin, 5 (Agrawal, 1989); and the triterpenes $2 \alpha, 3 \alpha-$ hydroxy-oleanolic acid, 15, $2 \alpha, 3 \beta$-hydroxy-oleanolic

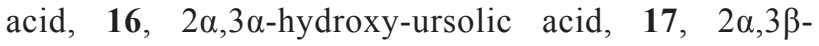
hydroxy-ursolic acid, 18, 2 $\beta, 3 \beta, 19 \alpha$-hydroxy-ursolic acid, 19, (Mahato \& Kundu, 1994), and 28-O-glucosyl$2 \alpha, 3 \alpha, 19 \alpha$-hydroxy-ursolic acid ester, 20 (Seto et al, 1984), were isolated. From the ethyl acetate extract, VA, orientin, 6, iso-orientin, 7, vitexin, 8, iso-vitexin, 
9, 2"-O-caffeoyl-orientin (Leitão \& Delle Monache, 1998), 11, 2"-O-p-hydroxybenzoyl-orientin, 10, (Leitão \& Delle Monache, 1998) protocatechuic acid, 12, vanilic acid, 13, and $p$-hydroxybenzoic acid, 14, were isolated. From the $n$-butanol extract, VB, orientin, 6, iso-orientin, 7, tarumal, 21, viteoid II, 22 and agnuside, 23, (Santos et al., 2001) were isolated.

\section{Acute toxicity}

In order to evaluate the possible toxic effects of $V$. cymosa extracts, mice were treated orally with 500 $\mathrm{mg} / \mathrm{kg}$ of each of them. Treated mice did not present any behavioral alterations. Also, stomachs were removed from the animals and examined under dissecting microscope. No lesions or bleedings were observed (data not shown).
Analgesic activity

To test the antinociceptive effects of Vitex cymosa extracts were used models of peripheral, spinal and supra-spinal analgesia.

Acetic acid-induced abdominal writhing

Intraperitoneal injection of acetic acid induced $100.1 \pm 3.9$ writhings in a period of $20 \mathrm{~min}$. Pre-treatment of mice with $V$. cymosa extracts in doses of 10, 30 and $100 \mathrm{mg} / \mathrm{kg}$ induced a dose-response reduction on total number of contortions. The most potent extract was VB (Figure 1). Even at $10 \mathrm{mg} / \mathrm{kg}, \mathrm{VB}$ significantly reduced in $25 \%$ (100.1 \pm 3.9 writhings in control group versus $73.4 \pm 4.0$ writhings in extract-treated group) the number<smiles>[R6]Oc1c([R3])c(O)c2c(=O)c([R])c(-c3ccc(O)c([R2])c3)oc2c1[R]</smiles>

$1 \mathrm{R}_{1}=\mathrm{OH}, \mathrm{R}_{2}=\mathrm{H}$

$2 \mathrm{R}_{1}=\mathrm{H}, \mathrm{R}_{2}=\mathrm{OCH}_{3}$

$3 \mathrm{R}_{1}=\mathrm{H}, \mathrm{R}_{2}=\mathrm{OH}$

$4 \mathrm{R}_{1}=\mathrm{R}_{2}=\mathrm{R}_{3}=\mathrm{OCH}_{3}$

$5 \quad \mathrm{R}_{1}=\mathrm{R}_{2}=\mathrm{R}_{3}=\mathrm{R}_{4}=\mathrm{R}_{5}=\mathrm{H}$

$6 \mathrm{R}_{1}=\mathrm{R}_{3}=\mathrm{R}_{5}=\mathrm{H}, \mathrm{R}_{2}=\mathrm{OH}, \mathrm{R}_{4}=\mathrm{Glu}$

$7 \mathrm{R}_{1}=\mathrm{R}_{3}=\mathrm{R}_{4}=\mathrm{H}, \mathrm{R}_{2}=\mathrm{OH}, \mathrm{R}_{5}=\mathrm{Glu}$

$8 R_{1}=R_{2}=R_{3}=R_{5}=H, R_{4}=$ Glu

$9 \mathrm{R}_{1}=\mathrm{R}_{2}=\mathrm{R}_{3}=\mathrm{R}_{4}=\mathrm{H}, \mathrm{R}_{5}=\mathrm{Glu}$

$10 \mathrm{R}_{1}=\mathrm{R}_{3}=\mathrm{R}_{5}=\mathrm{H}, \mathrm{R}_{2}=\mathrm{OH}, \mathrm{R}_{4}=\mathrm{X}$

$11 \mathrm{R}_{1}=\mathrm{R}_{3}=\mathrm{R}_{4}=\mathrm{H}, \mathrm{R}_{2}=\mathrm{OH}, \mathrm{R}_{5}=\mathrm{Y}$

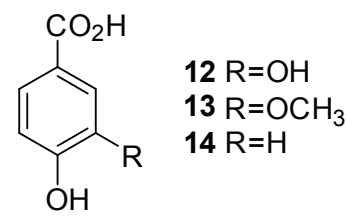

HO $\overbrace{\mathrm{HO}}^{\mathrm{O}} \mathrm{TOR}^{-\xi} \quad \begin{aligned} & \mathbf{X}=p \text {-hydroxybenzoyl } \\ & \mathrm{Y} \mathrm{R}=\text { caffeoyl }\end{aligned}$

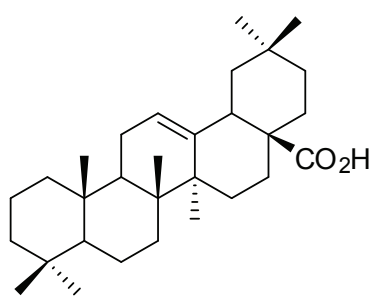

$152 \alpha, 3 \alpha \mathrm{OH}$ $162 \alpha, 3 \beta \mathrm{OH}$<smiles>CO[C@@H]1CC2C(C=O)=C(C)CC2O1</smiles>

21<smiles>O=C1OCC[C@H]2C(CO)=C(CO)C[C@H]12</smiles>

22

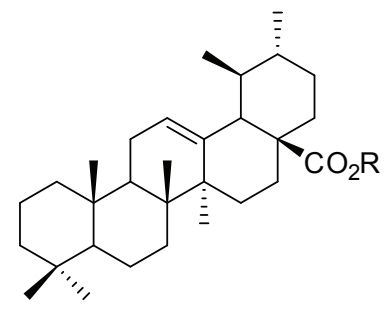

$172 \alpha, 3 \alpha \mathrm{OH}, \mathrm{R}=\mathrm{H}$

$182 \alpha, 3 \beta \mathrm{OH}, \mathrm{R}=\mathrm{H}$

$192 \beta, 3 \beta, 19 \alpha \mathrm{OH}, \mathrm{R}=\mathrm{H}$

$202 \alpha, 3 \alpha, 19 \alpha \mathrm{OH}, \mathrm{R}=\mathrm{Glu}$<smiles>O=C(OCC1=C[C@H](O)C2C=CO[C@H](O)C12)c1ccc(O)cc1</smiles> 
of writhings. At the doses of 30 and $100 \mathrm{mg} / \mathrm{kg}$ there was significant effect to all three fractions, VD, VA and VB (Figure 1).

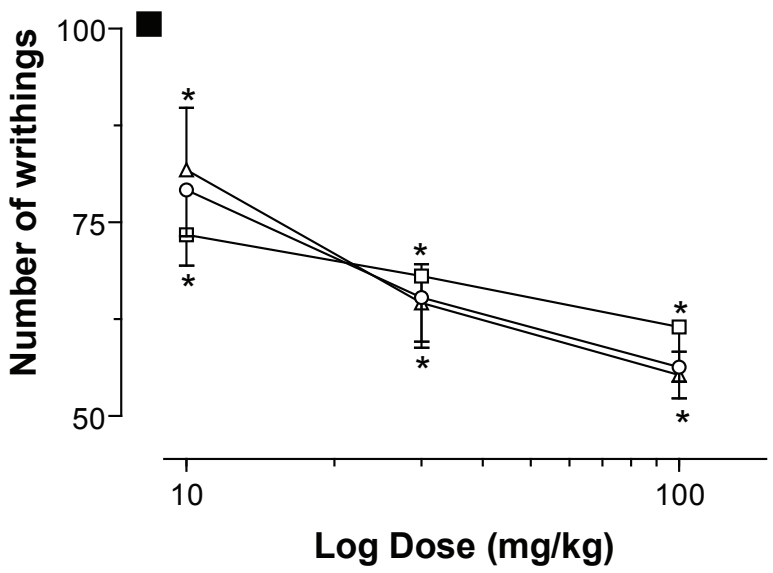

Figure 1. Effects of Vitex cymosa leaf extracts on acetic acidinduced writhings. Animals were pre-treated with extracts or vehicle by oral administration. Groups are: vehicle (匹), VD $(\Delta)$, VB ( $\square)$, or VA $(\circ)$. The results are presented as mean \pm SD; $(\mathrm{n}=10)$ of total writhings calculated as described on methods section. $* p<0.05$ ANOVA followed by Bonferroni's test

\section{Formalin test}

Intraplantar injection of formalin evoked a characteristic biphasic licking response. For the control group, the duration of licking in the $1^{\text {st }}$ phase was $48.8 \pm 11.7 \mathrm{~s}$, and for the $2^{\text {nd }}$ phase was $141.6 \pm 33.0 \mathrm{~s}$. As shown in Figure 2, pre-treatment with different doses of VD, VA or VB had no significant effect against the $1^{\text {st }}$ phase. However, $2^{\text {nd }}$ phase was markedly reduced by VD, with maximal effect observed with $100 \mathrm{mg} / \mathrm{kg}$. VA and VB developed significant effect on the $2^{\text {nd }}$ phase only at doses of 30 and $100 \mathrm{mg} / \mathrm{kg}$. However, VA effects were lesser pronounced than those of VB or VD. Results obtained demonstrated that VD was the most efficient in reducing the time that the animal spent licking the formalin-injected paw.

\section{Tail-flick and hot plate tests}

In view of the fact that $V$. cymosa extracts demonstrated significant antinociceptive activity on acetic acid-induced writhing and formalin tests, we decided to test its action on spinal and supraspinal models of pain - tail flick and hot plate tests. As shown in the Figure 3, all three extracts induced an increase in the time to withdrawal the tail from the bath (demonstrated as increase in baseline). Morphine $(2.3 \mathrm{mg} / \mathrm{kg}$ ) produced its maximum antinociceptive effect between 60 and 100 min after oral administration, with maximal values reaching $50 \%$ increase in baseline at $100 \mathrm{~min}$. The antinociceptive action of morphine lasted about $120 \mathrm{~min}$. Dichloromethane extract (VD) had similar curves to all doses tested, and reached maximal response 80 minutes after administration. Although VD induced an increase in the baseline, this was not a significant effect. VB extract developed a dose-response curve, with very little differences between each tested dose $(10,30$, and $100 \mathrm{mg} /$ $\mathrm{kg}$ ). Twenty minutes after VB administration a significant increase in the baseline could already be observed with all doses. At $120 \mathrm{~min}$, the antinociceptive effect of morphine began to decline, whereas the effect of VB continued at high levels within $120 \mathrm{~min}$, and lasted $2 \mathrm{~h}$ after a single oral administration (data not shown). The response to VA was quite different. Significant antinociceptive activity was observed at the dose of $100 \mathrm{mg} / \mathrm{kg}$. This effect appeared after 60 minutes of administration and was maintained until the end of the experiment.
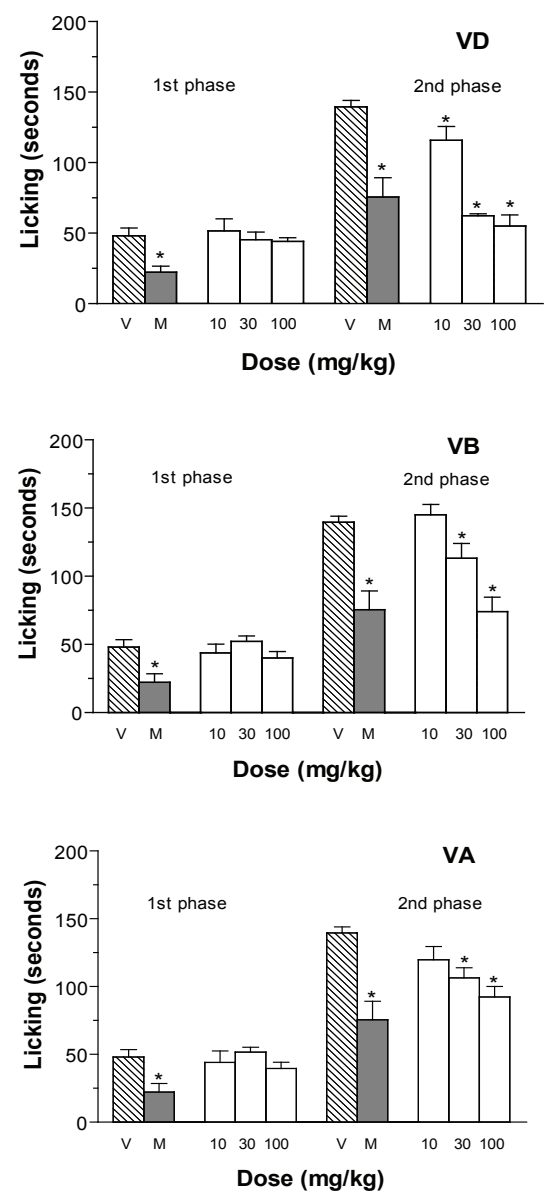

Figure 2. Effects of Vitex cymosa leaf extracts in the formalin test. Animals were pre-treated with different doses of extracts or vehicle by oral administration. Groups are: vehicle ( morphine $-1.7 \mathrm{mg} / \mathrm{kg}(\square)$ or extracts at different doses $(\square)$. The results are presented as mean \pm S.D. $(n=10)$ of time, in seconds, that the animal spent licking the injected paw calculated as described on methods section. Statistical significance was calculated by ANOVA followed by Bonferroni's test. ${ }^{*} p<0.05$ when compared with vehicle-treated mice. 

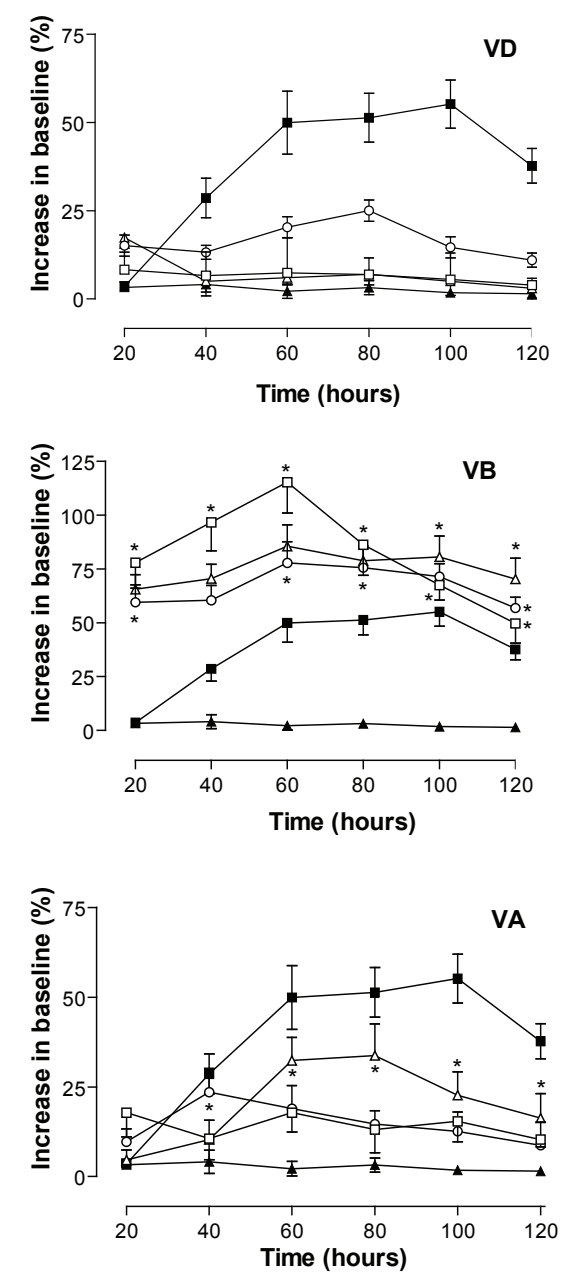

Figure 3. Effects of Vitex cymosa leaf extracts in the tail flick response. Animals were pre-treated with different doses of extracts or vehicle by oral administration. Groups are: vehicle $(\boldsymbol{\Delta})$, morphine $(2.3 \mathrm{mg} / \mathrm{kg}, \mathbf{\square})$, extracts at $10(\square), 30(\circ)$, or $100 \mathrm{mg} / \mathrm{kg}(\Delta)$. The results are presented as mean \pm SD. $(n=10)$ of increase in baseline (\%) calculated as described on methods section. Statistical significance was calculated by ANOVA followed by Bonferroni's test.* $p<0.05$ when compared with vehicle-treated mice. Where no error bars are shown is because they are smaller than the symbol.

To test the hypothesis that $V$. cymosa could have supraspinal analgesic effect, the hot plate model was used. Upon oral administration of $V$. cymosa extracts (at $100 \mathrm{mg} / \mathrm{kg}$ ), no antinociceptive effect was observed (data not shown).

\section{Mechanism of action}

In order to elucidate the mechanism by which $V$. cymosa extracts induce antinociceptive effect, animals were pre-treated with the non-selective opioid antagonist, naloxone. Figure 4 shows that naloxone (5 $\mathrm{mg} / \mathrm{kg})$ completely reverted the morphine $(2.3 \mathrm{mg} / \mathrm{kg})$ antinociceptive effect in tail flick model. Naloxone also reverted the antinociceptive activity of all $V$. cymosa extracts tested (at $30 \mathrm{mg} / \mathrm{kg}$ ). Results of naloxone against $V$. cymosa extracts were comparable to those obtained with naloxone against morphine on the spinal model of analgesia.

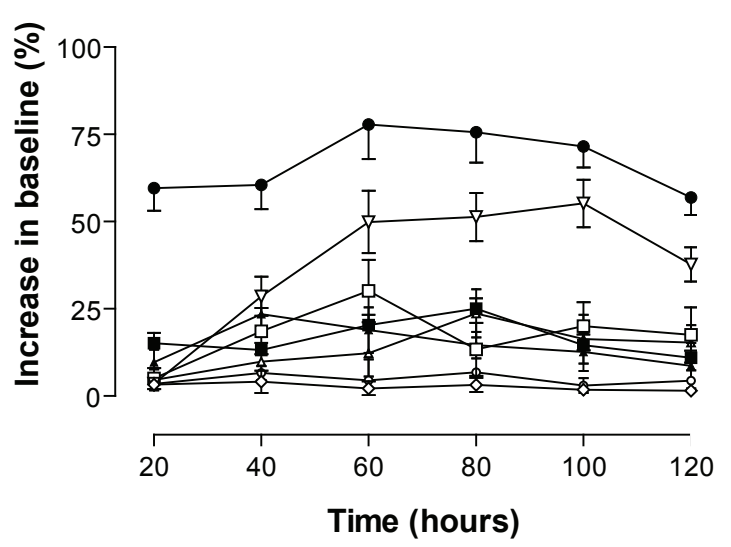

Figure 4. Effect of naloxone on the antinociceptive activity of Vitex cymosa leaf extracts. Animals were pre-treated with naloxone $(5 \mathrm{mg} / \mathrm{kg}$, i.p. $) 15 \mathrm{~min}$ before oral administration of extracts $(30 \mathrm{mg} / \mathrm{kg})$. Groups are: vehicle $(\diamond)$, morphine $(2.3 \mathrm{mg} /$ $\mathrm{kg}, \boldsymbol{\nabla})$, morphine + naloxone $(\nabla), \mathrm{VD}(\boldsymbol{\Delta}), \mathrm{VD}+$ naloxone $(\Delta)$, VA $(\bullet), \mathrm{VA}+$ naloxone $(\circ), \mathrm{VB}(\boldsymbol{\bullet}), \mathrm{VB}+$ naloxone $(\square)$. The results are presented as mean \pm S.D. $(n=10)$ of increase in baseline (\%) calculated as described on methods section. Statistical significance was calculated by ANOVA followed by Bonferroni's test. ${ }^{*} p<0.05$ when comparing extracts + naloxone or morphine+naloxone with extracts or morphine-treated mice. Where no error bars are shown is because they are smaller than the symbol.

\section{Discussion}

The purpose of this paper was to establish a scientific basis for one of the traditional uses of Vitex cymosa, which is against rheumatic pains. All tested extracts significantly inhibited the abdominal contortions induced by acetic acid in mice. Acetic acid causes an increase in peritoneal fluid levels of prostaglandins, involving in part, peritoneal receptors (Deraedt et al., 1980) and inflammatory pain by inducing capillary permeability (Amico-Roxas et al., 1984). Although the writhing test has poor specificity (Le Bars et al, 2001), it is a very sensitive method of screening antinociceptive effects of compounds. The acetic acid-induced writhing method is able to determine antinociceptive effects of compounds and dose levels that might appear inactive in other methods (Gene et al., 1998) This results indicate that Vitex cymosa presents antinociceptive activity. Despite the assayed extracts possess very different chemical compositions, they all consist of a varied class 
of compounds for which some kind of antinflammatory and/or analgesic activity has been described in literature. Flavonoids, for example, were detected in all the assayed Vitex cymosa extracts (VD, VA and VB). Several studies have reported the antinociceptive effects of flavonoids (Thirugnanasambantham et al., 1990; Pathak et al., 1991; Ramesh et al., 1998; Toker et al., 2004), and, of particular interest is that one reporting the antinociceptive activity of luteolin (Block et al., 1998), which was isolated from VD extract. The antinociceptive activity of this flavonoid has been evaluated by Block et al. (1998) in the acetic acid-induced abdominal constriction model in mice. Pharmacological analysis revealed that luteolin caused gradual and significant inhibition of abdominal writhings. When compared to acetylsalicylic acid, acetaminophen, dipyrone and indomethacin, by using the same pharmacological procedure, luteolin was about 8-16-fold more active than these standard drugs (Block et al., 1998). Luteolin was also detected, among other flavonoids, in extract of Vitex rotundifolia fruits (Emi et al., 1998). Thirugnanasambantham et al. (1990) showed that various synthetic flavone derivatives, structurally related to luteolin, displayed significant analgesic activity and suggested that some of them could be acting through an opiate-like mechanism. However, whether or not the antinociceptive action of luteolin involves such mechanism requires further investigations. Luteolin, together with apigenin, orientin and vitexin - which are present in Vitex cymosa extracts, were also isolated in a bioassay-guided fractionation of an antinociceptive extract from Zea mays stigmas (corn silk), which activity was evaluated by the $p$-benzoquinone-induced writhings and the formalin-induced edema models (Abdel-Wahab et al., 2002).

Concerning the isolated triterpenes, they are all hydroxyl-derivatives of ursolic and oleanolic acids, for which antinociceptive activity has been demonstrated previously by our group (Costa et al., 2003).

The presence of iridoids in the active extracts is also noteworthy. Although there are some reports on the anti-inflammatory activity for this class of compounds (Ghisalberti, 1998; Recio et al., 1994; Singh, et al., 1993) including a report from Vitex genus (Suksamrarn et al., 2002) pharmacological data on analgesic activity for this class of compounds is scarce. There is one report on the analgesic properties of agnuside (Okuyama et al., 1998) but no reports for the iridoids tarumal or viteoid II. It is interesting to note that Vitex cymosa is used in the Brazilian traditional medicine to treat rheumatoid arthritis. Also noteworthy, is the fact that one of the most prescribed phytomedicines to treat degenerative diseases of the musculoskeletal system nowadays is the South African plant Harpagophytum procumbens D.C., known as Devil's Claw, which active principles are claimed to be iridoid glucosides (Stewart \& Cole, 2005; Baghdikian et al., 1997).

The neurogenic and inflammatory pain was evaluated using formalin test. Drugs that act primarily as central analgesics inhibit both phases while peripherally acting drugs inhibit only the phase 2 (Rosland et al., 1990). We observed that none of $V$. cymosa extracts was able to decrease the time that the animal spent licking the injected paw on the first phase, while the second phase was inhibited by all tested extracts, specially VD. The presence of dihydroxy- and trihydroxy derivatives of oleanolic and ursolic acids in this extract is noteworthy, since, in a previous work from our group, we have demonstrated the analgesic potential of a mixture of ursolic, oleanolic and micrometric acids, in the same models reported here (Costa et al., 2003). Inhibition of the second phase alone, (Rosland et al, 1990), suggests a peripheral antinociceptive activity of Vitex cymosa. These results corroborate with the inhibitory effect of $V$. cymosa extracts on the acetic acid-induced writhing response.

Several studies demonstrated that opioids can produce analgesia through peripheral mechanisms after inflammation of tissues (Stein et al., 1989, 1996). $V$. cymosa extracts produced antinociceptive effect in the formalin test in mice after oral administration. These findings are in agreement with others studies where antinociceptive effects of peripherally acting $\mu$ opioid agonist, loperamide, were detected in the formalin test after subcutaneous administration (Shannon \& Lutz, 2002). The peripheral antinociceptive activity produced by opioid system is based on the opening of potassium channels, causing hyperpolarization in nociceptive afferents. (Milan, 1999).

In order to verify if $V$. cymosa extracts could develop central antinociceptive effect, the models of tail flick (spinal analgesia) and hot plate (supra-spinal analgesia) were used. Extracts from the leaves of $V$. cymosa were able to increase latency time in the tail flick. In this model, after the thermal stimulus applied to the tail, superficial tissue layers are broadly stimulated and a tail withdrawal reflex is evoked, which characterizes spinal mechanism and involves sensory and motor components (Green \& Young, 1951). The rapid onset with an early maximum effect, which warred very shortly after drug administration, is characteristic of the time course of action of opioid agonists (e.g. morphine, fentanyl and etorphine) that mediate analgesia via central mechanisms and were described under both normal and inflammatory conditions (Aceto et al., 1997; Millan et al., 1987). Administration of VD, VB, and VA produced different time course of action. VD did not evoke a significant effect and, the antinociceptive effect of VA was observed only with a higher dose. VB, however, showed a rapid onset and longer-lasting action than 
the centrally acting opioids, with higher effects. In this way, these results presented in the tail flick test show spinal antinociceptive activity by the $V$. cymosa extracts. The spinal antinociceptive activity is associated with a reduction in the release of excitatory neurotransmitters (glutamate, substance $\mathrm{P}$ etc.) at the spinal cord, and hyperpolarization of ascending neurons (Besson \& Chaouch, 1987). In the hot plate test, the antinociceptive activity was not observed probably due to the difficulty in crossing the blood-brain barrier by the active molecules of $V$. cymosa extracts, revealing a probable supraspinal antinociceptive effect if the active molecules were administered by intracerebroventricular route. (Grisel \& Mogil, 2000). The supraspinal antinociceptive activity is related to activation of the endogenous inhibitory control of pain. (Saadé \& Jabbur; 2008).

The reduction of the antinociceptive effect of the extracts produced by the prior administration of naloxone, a non-selective opioid antagonist, shows the participation of the opioid system in the mechanism of action of extracts of Vitex cymosa, proving the involvement of this system in the peripheral, spinal and supraspinal antinociceptive actions. Together, these data are consistent with the interpretation that systemically administered morphine exerts its analgesic effects by interacting with both central and peripheral opioid receptors (Perrot et al., 2001; Shannon \& Lutz, 2002).

\section{Conclusions}

The lactone (+)-trans-4-hydroxy-6-propyl1-oxocyclohexan-2-one which was determined to be the active principle of $V$. cymosa dichloromethane bark extracts could not be isolated from the dichloromethane extracts from the leaves. The exact mechanism of action and the active principles responsible for the analgesic activities described here remain to be confirmed, but taking all these in vivo results together, it can be suggested that Vitex cymosa leaf extracts were able to promote peripheral and central antinociceptive activity mediated by the opioid system.

\section{Acknowledgements}

This work was supported by FAPERJ and CNPq. We are indebted to Dr. Vali Pott for plant collection and identification.

\section{References}

Abdel-Wahab SM, El-Tanbouly ND, Kassem HA, Mohamed EA 2002. Phytochemical and biological study of corn silk (styles and stigmas of Zea mays L.). Bull Fac Pharm 40: 93-102.

Aceto MD, Harris LS, Bowman ER 1997. Etorphines: $\mu$-opioid receptor-selective antinociception and low physical dependence capacity. Eur J Pharmacol 338: 215-223.

Agrawal PK 1989 Carbon-13 NMR of Flavonoids. Elsevier Science Publishers B.V., New York, USA.

Amico-Roxas M, Caruso A, Trombadore S, Scifo R, Scapagnini U 1984. Gangliosides antinociceptive effects in rodents. Arch Internation Pharmacodyn Ther 272: 103-117.

Baghdikian B, Lanhers MC, Fleurentin J, Ollivier E, Maillard C, Balansard G, Mortier F 1997. An analytical study, antiinflammatory and analgesic effects of Harpagophytum procumbens and Harpagophytum zeyheri. Planta Med 63: 171-176.

Besson JM, Chaouch A 1987. Peripheral and spinal mechanisms of nociception. Physiol Rev 67: 67-186

Bhargava SK 1989. Antiandrogenic effects of a flavonoid-rich fraction of Vitex negundo seeds: a histological and biochemical study in dogs. J Ethnopharmacol 27: $327-$ 339.

Block LC, Santos ARS, Souza MM, Scheidt C, Yunes RY, Santos MA, Delle Monache F, Filho VC 1998. Chemical and pharmacological examination of antinociceptive constituents of Wedelia paludosa. J Ethnopharmacol 61: 85-89.

Boros CA, Stermitz FR 1990. Iridoids. An updated review. Part I. J Nat Prod 53: 1055-1147.

Brito NRS 1992. Contribuição à farmacognosia de Verbenaceae I. O gênero Vitex L. Rev Bras Farm 73: 19-23. Esse trabalho não é da RBFAR

Chawla AS, Sharma AK, Handa SS 1991. Chemical investigation and antiimflamatory activity of Vitex negundo seeds: Part I. Indian J Chem 30B: 773-776.

Correa MP 1926. Dicionário das Plantas Úteis do Brasil e das Exóticas Cultivadas. Imprensa Nacional, Rio de Janeiro, Brasil.

Costa VB, Coube CS, Marinho BG, Matheus ME, Leitão SG, Fernandes PD 2003. Anti-imflammatory and analgesic activity of Bouchea fluminensis. Fitoterapia 74: 364371.

Dayrit FM, Lapid MRG, Cagampang JV, Lagurin LG 1987. Phytochemical studies on the leaves of Vitex negundo L., ("Lagundi") I. Investigations of the bronchial relaxing constituents. Philippine J Sci 116: 403-410.

Dayrit FM, Lagurin LG 1994. Identification of iridoids in the pharmacologically-active fraction of Vitex negundo L. Philippine J Sci 123: 292-299.

Deraedt R, Jougney S, Delevalcee F, Falhout M 1980. Release of prostaglandin $\mathrm{E}$ and $\mathrm{F}$ in an algogenic reaction and its inhibition. Eur J Pharmacol 51: 17-24.

Emi O, Kuniharu S, Mikio Y 1998. Pharmacologically active components of Viticis Fructus (Vitex rotundifolia). I. The components having vascular relaxation effects. Nat Med 52: 218-225.

Gallo MBC, Beltrame FL, Vieira PC, Cass QB, Fernandes JB, Silva MFGF 2006. Quantitative determination of 20hydroxyecdysone in methanolic extract of twigs from 
Vitex polygama Cham. J Chromatogr B 832: 36-40.

Gallo MBC, Vieira PC, Fernandes JB, Silva MFGF, Salimena FR 2008. Compounds from Vitex polygama active against kidney diseases. $J$ Ethnopharmacol 115: 220222.

Gene RM, Segura L, Adzet T, Marin E, Inglesias J 1998. Heterotheca inuloides: antiinflammatory and analgesic effects. J Ethnopharmacol 60: 157-62.

Ghisalberti EL 1998. Biological and pharmacological activity of naturally occurring iridoids and secoiridoids. Phytomedicine 5: 147-163.

Gomes NM, Rezende CM, Fontes SP, Matheus ME, Fernandes PD 2007. Antinociceptive activity of Amazonian copaiba oils. J Ethnopharmacol 109: 486-492.

Gonçalves JLS, Leitão SG, Miranda MMFS, Santos MGM, Romanos MTV, Delle Monache F, Wigg MD 2001. In vitro antiviral effect of flavonoid-rich extracts of Vitex polygama (Verbenaceae) against aciclovir-resistant herpes simplex virus type1. Phytomedicine 8: 477-480.

Green AF, Young PAA 1951. A comparison of heat and pressure analgesiometric methods in rats. Brit $J$ Pharmacol 6: $572-87$.

Grisel JE, Mogil JS 2000. Effects of supraspinal orphanin FQ/ nociceptin. Peptides 21: 1037-1045.

Le Bars D, Gozariu M, Cadden S 2001. Animal models of nociception. Pharmacol Rev 53: 597-652.

Leitão SG, Delle Monache F 1998. 2"-O-caffeoylorientin from Vitex polygama. Phytochemistry 49: 2167-2169.

Leitão SG, Fonseca EN, Santos TC, França F, Delle Monache F 2008. Caffeoylquinic acid derivatives from two Brazilian Vitex species. Biochem Syst Ecol 36: 312315.

Lorke D 1983. A new approach to practical acute toxicity testing. Arch Toxicol 54: 275-287.

Mahato R, Kundu A 1994. 13C-NMR spectra of pentacyclic triterpenoids - a compilation and some salient features. Phytochemistry 37: 1517-1575.

Matheus ME, Berrondo LF, Vieitas EC, Menezes FS, Fernandes PD 2005. Evaluation of the antinociceptive properties from Brillantaisia palisotii Lindau stems extracts. $J$ Ethnopharmacol 102: 377-381.

Milan MJ 1999.The induction of pain: an integrative review. Prog Neurobiol 57: 1-164.

Millan MJ, Czlonkowski A, Pilcher CWT, Almeida OFX, Millan MH, Colpaert FC, Herz A 1987. A model of chronic pain in the rat: functional correlates of alterations in the activity of opioid systems. J Neurosci 7: 77-87.

Miranda LSM, Marinho BG, Costa JS, Leitão SG, Santos TC, Delle Monache F, Fernandes PD, Vasconcellos MLAA, Pereira VLP 2010. Structural determination Vitex cymosa Bertero active principle: Diastereoselective synthesis of ( $( \pm)$-trans-4-hydroxy-6-propyl-1oxocyclohexan-2-one and its antinociceptive activity. Bioorg Chem 28: 181-185.

Mills S, Bone K 2000. Principles and practice of phytotherapy -
Modern herbal medicine. 1st ed., Churchill Livingstone, London.

Okuyama E, Fujimori S, Yamazaki M, Deyama T 1998. Pharmacologically active components of Viticis fructus (Vitex rotundifolia). II. The components having analgesic effects. Chem Pharm Bull 46: 655-662.

Pathak D, Pathak K, Sigla AK 1991. Flavonoids as medicinal agents: recent advances. Fitoterapia 62: 371-388.

Perrot S, Guilbaud G, Kayser V 2001. Differential behavioral effects of peripheral and systemic morphine and naloxone in a rat model of repeated acute inflammation. Anesthesiol 94: 870-875.

Ramesh M, Nageshwar Rao Y, Appa Rao AVN, Prabhakar MC, Rao CS, Muralidhar N, Reddy BM 1998. Antinociceptive and anti-inflammatory activity of a flavonoid isolated from Caralluma attenuate. J Ethnopharmacol 62: 6366.

Recio MD, Giner RM, Manez S, Rios JL 1994. Structural considerations on the iridoids as antiinflammatory agents. Planta Med 60: 232-234.

Rosland JH, Tjolsen A, Maehle B, Hole DK 1990. The formalin test in mice. Effect of the formalin concentration. Pain 42: $235-42$.

Saadé NE, Jabbur SJ 2008. Nociceptive behavior in animal models for peripheral neuropathy: Spinal and supraspinal mechanisms. Prog Neurobiol 86: 22-47.

Sá Barreto LCL, Xavier HS, Barbosa-Filho JM, BrazFilho R 2005. Ecdisteróide e iridóide glicosilado de Vitex gardneriana Schauer (Verbenaceae). Rev Bras Farmacogn 15: 51-54.

Santos TC, Schripsema J, Delle Monache F, Leitão SG 2001. Iridoids from Vitex cymosa. J Braz Chem Soc 12: 763766.

Seto T, Tanaka T, Tanaka O, Naruhashi N 1984. Glucosyl esters of $19 \alpha$-hydroxyursolic acid derivatives in leaves of Rubus species. Phytochemistry 23: 2829-2834.

Singh GB, Bani S, Singh S, Khajuria A, Sharma Ml, Gupta BD, Banerjee SK 1993. Antiinflammatory activity of the iridoids kutkin, picroside-1 and kutkoside from Picrorhiza kurrooa. Phytother Res 7: 402-407.

Shannon HE, Lutz EA 2002. Comparison of the peripheral and central effects of the opioid agonists loperamide and morphine in the formalin test in rats. Neuropharmacol 42: 253-261.

Sidhartha PS, Srinivasa-Aithal K, Srinivasan KK 1990. Antiinflammatory and wound healing activities of the crude alcoholic extract and flavonoids of Vitex leucoxylon. Fitoterapia 61: 263-265.

Stein C, Millan MJ, Shippenberg TS, Peter K, Herz A 1989. Peripheral opioid receptors mediating antinociception in inflammation. Evidence for involvement of $\mu, \delta$ and $\kappa$ receptors. J Pharmacol Exper Ther 248: 1269-1275.

Stein C, Pflüger M, Yassaouridis A, Hoelzl J, Lehrberger K, Welte C 1996. No tolerance to peripheral analgesia in presence of opioid expression in inflamed synovia. $J$ 
Clin Invest 98: 793-799.

Stewart KM, Cole D 2005. The commercial harvest of devil's claw (Harpagophytum spp.) in southern Africa: The devil's in the details. J Ethnopharmacol 100: 225-236.

Suksamrarn A, Kumpun S, Kirtikara K, Yingyongnarongkul B, Suksamrarn S 2002. Iridoids with anti-inflammatory activity from Vitex peduncularis. Planta Med 68: $72-$ 73.

Thirugnanasambantham P, Viswanathan S, Mythirayee C, Krishnamurty V, Santa Ramachandran, Karmeswaran L 1990. Analgesic activity of certain flavone derivatives: a structure-activity study. J Ethnopharmacol 28: 207 214.

Toker G, Küpeli E, Memisoglu M, Yesilada E 2004. Flavonoids with antinociceptive and anti-inflammatory activities from the leaves of Tilia argentea (silver linden). $J$
Ethnopharmacol 95: 393-397.

You KM, Son KH, Chang HW, Kang SS, Kim HP 1998. Vitexicarpin, a flavonoid from Vitex rotundifolia, inhibits mouse lymphocyte proliferation and growth of cell lines in vitro. Planta Med 64: 546-550.

\section{*Correspondence}

\section{Suzana Guimarães Leitão}

Departamento de Produtos Naturais e Alimentos, Faculdade de Farmácia, Universidade Federal do Rio de Janeiro

CCS, Bloco A, 2o andar salas 4 e 10, Ilha do Fundão, 21941590, Rio de Janeiro-RJ, Brazil

sgleitao@pharma.ufrj.br

Tel/Fax: +55 212562 6413/6425 